\title{
Avaliação da inibição da acetilcolinesterase por extratos de plantas medicinais
}

\author{
MOTA, W.M.; BARROS, M.L.; CUNHA, P.E.L.; SANTANA, M.V.A.; STEVAM, C.S.; LEOPOLDO, P.T.G., \\ FERNANDES, R.P.M.* \\ Departamento de Fisiologia, Centro de Ciências Biológicas e da Saúde, Universidade Federal de Sergipe (UFS), \\ Avenida Marechal Rondon, S/N, Jardim Rosa Elze, CEP: 49100-000, São Cristóvão-Brasil \\ *robertafernandes@ufs.br
}

\begin{abstract}
RESUMO: Neste trabalho foi avaliada a atividade inibitória da acetilcolinesterase (AChE) pelo método de Ellman, modificado por Rhee, de extratos aquosos e etanólicos de oito plantas utilizadas na medicina popular da região Nordeste do Brasil. O extrato aquoso de $E$. velutina não apresentou atividade inibitória enquanto o extrato aquoso de Maytenus rigida apresentou baixa atividade inibitória (percentual de inibição de 4\%). Detectou-se atividade inibitória moderada com o extrato aquoso de $P$. piperoides (percentual de inibição de $40 \%$ ), enquanto o extrato de $V$. agnus-castus L. inibiu $74 \%$ da atividade da AChE, caracterizando-se como potente atividade inibitória. Aavaliação da inibição da AChE com os extratos etanólicos demonstrou que os extratos de Sideroxylon obtusifolium, Erythrina velutina, Vitex agnus-castus, Phoradendron piperoides, Chrysobalanus icaco, Bauhinia cheilantha e Orbignya phalerata não apresentaram atividade inibitória. Baixa atividade inibitória foi observada com os extratos etanólicos de Maytenus rigida (percentual de inibição de $7 \%$ ) e de Hyptis fruticosa (percentual de inibição de $11 \%$ ). O extrato etanólico de Moringa oleifera apresentou atividade inibitória moderada, inibindo $47 \%$ da atividade dessa enzima. Nenhum dos extratos etanólicos testados apresentou atividade inibitória potente da AChE. Os resultados dos estudos de inibição da acetilcolinesterase permitem concluir que o extrato aquoso de $V$. agnus-castus L. mostrou-se o mais eficaz quanto a inibição da AChE. Este resultado reforça a necessidade da continuidade do estudo desse extrato, de forma a realizar a partição do extrato e a purificação das frações para isolar a molécula responsável pela inibição observada.
\end{abstract}

Palavras-chave: extrato aquoso, extrato etanólico, inibição enzimática

ABSTRACT: Evaluation of acetylcholinesterase inhibition by extracts from medicinal plants. In this study, we evaluated the inhibitory activity against acetylcholinesterase (AChE) according to Ellman's method, modified by Rhee, for ethanol and aqueous extracts from eight plants used in folk medicine in the northeast region of Brazil. E. velutina aqueous extract did not have inhibitory activity, while Maytenus rigida aqueous extract showed low inhibitory activity (percentage of inhibition of 4\%). Moderate inhibitory activity was detected for Phoradendron piperoides aqueous extract (percentage of inhibition of $40 \%$ ), while $V$. agnus castus L. extract inhibited $74 \%$ AChE activity, characterized as a potent inhibitory activity. Evaluation of AChE inhibition by ethanol extracts indicated that the extracts from Sideroxylon obtusifolium, Erythrina velutina, Vitex agnus-castus L., Phoradendron piperoides, Chrysobalanus icaco, Bauhinia cheilantha and Orbignya phalerata did not show inhibitory activity. A low inhibitory activity was observed for ethanol extracts from Maytenus rigida (percentage of inhibition of $7 \%$ ) and Hyptis fruticosa (percentage of inhibition of $11 \%$ ). Moringa oleifera ethanol extract showed moderate inhibitory activity, inhibiting $47 \%$ of the activity of this enzyme. None of the tested ethanol extracts showed potent inhibitory activity againstAChE. Results of the studies of acetylcholinesterase inhibition allow the conclusion that $V$. agnus-castus $L$. aqueous extract showed to be most effective in inhibiting AChE. This result reinforces the need for continued study of this extract in order to make the partition and the purification of fractions to isolate the molecule responsible for the observed inhibition.

Key words: aqueous extract, ethanol extract, enzyme inhibition

Recebido para publicação em 05/11/2010

Aceito para publicação em 24/05/2012

Rev. Bras. PI. Med., Botucatu, v.14, n.4, p.624-628, 2012. 


\section{INTRODUÇÃO}

A acetilcolina (ACh) é um neurotransmissor bastante difundido por todo o sistema nervoso. No sistema nervoso periférico, ela é liberada por todos os neurônios motores do sistema nervoso somático e, no sistema nervoso autônomo, por todos os neurônios pré-ganglionares, além dos neurônios pósganglionares do sistema nervoso parassimpático e dos pós-ganglionares que inervam as glândulas sudoríparas, pertencentes ao sistema nervoso simpático. Já no sistema nervoso central, a ACh é amplamente distribuída por todo o cérebro, particularmente nas regiões do córtex cerebral, prosencéfalo basal, hipocampo, diencéfalo, ponte e, em menor quantidade, no cerebelo. Os neurônios colinérgicos estão relacionados com importantes funções como o alerta, o controle motor, o aprendizado e a memória, e todas essas ações exercidas pela ACh estão prejudicadas quando há deficiências na secreção desse neurotransmissor (Vinutha et al., 2007).

A acetilcolinesterase (AChE) é uma enzima cuja ação é crucial na propagação do impulso nervoso. A AChE inativa a ação do neurotransmissor acetilcolina hidrolisando-o em acetato e colina. A acetilcolina é sintetizada e armazenada em vesículas no neurônio pré sináptico, sendo que a liberação depende de alterações iônica e elétrica da membrana plasmática. A despolarização da membrana plasmática do neurônio pré sináptico promove o influxo de $\mathrm{Ca}^{2+}$ seguida de fusão de vesículas sinápticas com a membrana plasmática. Essa fusão promove a liberação de acetilcolina na fenda sináptica e difusão até o receptor localizado na membrana plasmática do neurônio pós-sináptico. Antes que ocorra nova liberação de acetilcolina, a molécula previamente liberada deve ser hidrolisada pela AChE.

$\mathrm{Na}$ doença de Alzheimer (DA), complexa e progressiva doença neurodegenerativa multifatorial, atingindo primordialmente a população idosa com mais de 65 anos de idade (Adams et al., 2007) são observados déficits cognitivos e funcionais. Evidências demonstram que esses déficits relacionam-se com a degeneração do sistema colinérgico, devido principalmente a diminuição dos níveis plasmáticos de acetilcolina (Vinutha et al., 2007). Pacientes de DA apresentam melhora dos sintomas cognitivos, comportamentais e funcionais relacionados às demências hipocolinérgicas, quando tratados com inibidores de AChE (OH et al., 2004). Esses inibidores aumentam os níveis de acetilcolina presentes nas sinapses entre neurônios colinérgicos (Jung \& Park, 2007).

Um número reduzido de fármacos é utilizado no tratamento da DA (Lin et al., 2008), entre eles já são aprovados para o tratamento os medicamentos sintéticos tacrina, donepezila e rivastigmina e princípios extraídos de plantas como galantamina. A rivastigmina $\left(\right.$ Exelon $\left.^{\circledR}\right)$ é obtida a partir do alcalóide fisiostigmina, também inibidor da AChE (Mukherjee et al., 2007). A galantamina pode ser isolada de diversas espécies dos gêneros Galanthus e Narcissus da família Amaryllidaceae, mas atualmente produzido sinteticamente, é considerada a mais efetiva no tratamento da doença de Alzheimer. Esses medicamentos apresentam diversos efeitos colaterais tais como hepatotoxicidade, problemas gastrintestinais e relacionados com a biodisponibilidade desse fármaco, como tacrina, com curta meia vida (Murebwayirea et al., 2009 ). Além disso, a eficiência desses medicamentos é somente sobre a fase leve e moderada da doença, que representa um período curto.

Tendo em vista a grande utilidade dos inibidores da AChE na medicina e o limitado arsenal terapêutico para o tratamento da DA (Newman \&Cragg, 2007), bem como os problemas relacionados com esta terapêutica, este trabalho teve como objetivo a avaliação in vitro da atividade inibitória da AChE por extratos aquosos e etanólicos de Bauhinia cheilantha (mororó), Chrysobalanus icaco (grageru), Erythrina velutina (murungu), Hyptis fruticosa (alecrim de tabuleiro), Moringa oleifera (moringa), Maytenus rigida, Phoradendron piperoides (sucupira), Sideroxylon obtusifolium (quixabeitra) e Vitex agnus-castus L. (Alecrim-de-Angola) plantas medicinais bastante utilizadas na região Nordeste do Brasil.

\section{MATERIAL E MÉTODO}

$\mathrm{Na}$ Tabela 1 são apresentadas as plantas medicinais utilizadas no preparo de extratos para avaliação da atividade inibitória da enzima AChE.

Para o preparo dos extratos aquosos e alcoólicos foram utilizadas diferentes partes das plantas (Tabela 2). O material foi seco à temperatura ambiente, triturado e pulverizado, seguido de adição de etanol a $90 \%$ em percolador de aço inoxidável, durante cinco dias. Após concentração do solvente em evaporador rotativo, sob pressão reduzida, obtevese o extrato etanólico bruto. Para o preparo do extrato aquoso o material triturado e pulverizado, como descrito acima, foi extraído por decocção com 900 $\mathrm{mL}$ de água destilada. Após a extração, o material foi filtrado a vácuo e liofilizado. Para a avaliação da inibição da acetilcolinesterase, $10 \mathrm{mg}$ do extrato foi diluído em $1 \mathrm{~mL}$ de metanol.

A atividade enzimática da acetilcolinesterase foi determinada em microplacas pelo método espectrofotométrico de Ellman, modificado por Rhee et al. (2001). A enzima utilizada foi a acetilcolinesterase (AChE) de Electrophorus electricus tipo VI (Sigma ${ }^{\circledR}$ ), o 5,5'-dithiobis (ácido 2-nitrobenzoico) (DTNB), o substrato acetilcolina iodada e a eserina, foram 
TABELA 1. Espécies utilizadas para o preparo dos extratos usados no testes de inibição da acetilcolinesterase.

\begin{tabular}{|c|c|c|c|c|}
\hline Nome científico & Família & $\begin{array}{l}\text { Nome } \\
\text { comum }\end{array}$ & $\begin{array}{l}\text { Local/época } \\
\text { coleta }\end{array}$ & $\begin{array}{c}\text { № da } \\
\text { exsicata }\end{array}$ \\
\hline $\begin{array}{c}\text { Bauhinia cheilantha (Bong) } \\
\text { Steud }\end{array}$ & Cercideae & $\begin{array}{l}\text { Mororó-do- } \\
\text { sertão }\end{array}$ & $\begin{array}{l}\text { Lago do Xingó } \\
\text { Piranhas - AL }\end{array}$ & ASE 2870 \\
\hline Chrysobalanus icaco L. & Chrysobalanaceae & Gragerú & $\begin{array}{l}\text { Povoado } \\
\text { Jatobá - SE }\end{array}$ & ASE11855 \\
\hline Erythrina velutina W illd & Fabaceae & Mulungu & $\begin{array}{l}\text { Campus UFS } \\
\text { São Cristóvão- } \\
\text { SE 09/2006 }\end{array}$ & ASE 13163 \\
\hline $\begin{array}{c}\text { Hyptis fruticosa Salzm. ex. } \\
\text { Benth }\end{array}$ & Verbanaceae & $\begin{array}{l}\text { Alecrim-de- } \\
\text { tabuleiro }\end{array}$ & $\begin{array}{l}\text { Campus UFS } \\
\text { São Cristóvão, } \\
\text { SE } 07 / 2003\end{array}$ & ASE 01137 \\
\hline Maytenus rigida & Celastraceae & $\begin{array}{c}\text { Bom nome, } \\
\text { Pau de } \\
\text { colher }\end{array}$ & $\begin{array}{c}\text { Jeremoabo, } \\
\text { Bahia, } \\
\text { 10/2006 }\end{array}$ & ASE 9613 \\
\hline Moringa oleifera & Moringaceae & Moringa & $\begin{array}{l}\text { Campus UFS } \\
\text { São Cristóvão- } \\
\text { SE 04/2002 }\end{array}$ & ASE8288 \\
\hline $\begin{array}{l}\text { Phoradendron piperoides } \\
\text { (Kunth) Trel. }\end{array}$ & Viscaceae & $\begin{array}{l}\text { Enxerto de } \\
\text { passarinho }\end{array}$ & $\begin{array}{l}\text { Campus UFS } \\
\text { São Cristóvão- } \\
\text { SE 03/2006 }\end{array}$ & ASE05681 \\
\hline $\begin{array}{l}\text { Sideroxylon obtusifolium } \\
\text { (Roem \& Schult) T.D. Penn. }\end{array}$ & Sapotaceae & Quixabeira & $\begin{array}{l}\text { Lago do Xingó } \\
\text { Piranhas - AL }\end{array}$ & ASE 13163 \\
\hline Vitex agnus-castus L. & Verbanaceae & $\begin{array}{l}\text { Pimenta da } \\
\text { costa }\end{array}$ & $\begin{array}{l}\text { Campus UFS } \\
\text { São Cristóvão- } \\
\text { SE 09/2007 }\end{array}$ & ASE 4521 \\
\hline
\end{tabular}

TABELA 2. Espécies, partes usadas na produção dos extratos e tipos de extratos utilizados nos testes de inibição da acetilcolinesterase.

\begin{tabular}{ccc}
\hline Nome científico & Parte usada & Tipo de extrato \\
\hline Bauhinia cheilantha & Casca & Etanólico \\
Chrysobalanus icaco & Folhas & Etanólico \\
Erythrina velutina & Folhas & Aquoso \\
Erythrina velutina & Folhas & Etanólico \\
Hyptis fruticosa & Folhas & Etanólico \\
Phoradendron piperoides & Folhas & Aquoso \\
Phoradendron piperoides & Folhas & Etanólico \\
Maytenus rigida & Entrecasca & Etanólico \\
Maytenus rigida & Entrecasca & Aquoso \\
Moringa Oleifera & Semente & Etanólico \\
Sideroxylon obtusifolium & Folhas & Etanólico \\
Vitex agnus-castus L. & Folhas & Aquoso \\
Vitex agnus-castus L. & Folhas & Etanólico \\
\hline
\end{tabular}

Rev. Bras. PI. Med., Botucatu, v.14, n.4, p.624-628, 2012. 
obtidos da Sigma ${ }^{\circledR}$. Em cada poço das microplacas foram adicionados $25 \mu \mathrm{L}$ de acetilcolina iodada 15 $\mathrm{mM}, 125 \mu \mathrm{L}$ de DTNB, $50 \mu \mathrm{L}$ de tampão Tris-HCl 50

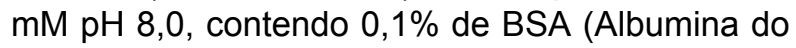
Soro Bovino) e $25 \mu \mathrm{L}$ dos extratos das plantas (Tabela 1) em concentração de $1 \mathrm{mg} \mathrm{mL}^{-1}$ (concentração final no ensaio de $0,1 \mathrm{mg} \mathrm{mL}^{-1}$ ). Metanol e tris- $\mathrm{HCl}$ foram usados como controles e eserina $(10 \mu \mathrm{M})$, como inibidor padrão. A absorbância foi medida 5 vezes a $405 \mathrm{~nm}$ utilizando o leitor de microplaca Thermoplate ${ }^{\circledR}$, modelo TP-reader, com intervalos de 15s, após essas leituras foram adicionados nos poços $25 \mu \mathrm{L}$ de acetilcolinesterase $0,22 \mathrm{U} \mathrm{mL}^{-1}$. As absorbâncias eram medidas novamente 9 vezes a $405 \mathrm{~nm}$, com intervalos de 15s.

Aumentos na absorbância devido à hidrólise espontânea do substrato foram corrigidos pela subtração da taxa de reação antes da adição da enzima. A porcentagem de inibição foi calculada pela comparação das taxas das amostras com os controles. Todos os ensaios foram realizados em triplicata. A atividade enzimática e o percentual de inibição da AChE foram calculados utilizando o programa Microsoft ${ }^{\circledR}$ Excel.

\section{RESULTADO E DISCUSSÃO}

A Tabela 3 apresenta os percentuais de inibição da atividade da AChE por extratos aquosos e etanólicos de Bauhinia cheilantha, Chrysobalanus icaco, Erythrina velutina, Hyptis fruticosa, Moringa oleifera, Phoradendron piperoides, Sideroxylon obtusifolium e Vitex agnus-castus. Dos 8 extratos testados para a avaliação da inibição daAChE (Tabela
3), os extratos etanólicos de Sideroxylon obtusifolium, Erythrina velutina, Vitex agnus-castus L., Phoradendron piperoides, Chrysobalanus icaco, e Bauhinia cheilantha, assim como o extrato aquoso de $E$. velutina, não apresentaram atividade inibitória sobre a acetilcolinesterase. Vinutha et al. (2007), em seu estudo de inibição da AChE com extratos de plantas medicinais indianas, propôs a classificação dos extratos analisados em: inibidores potentes (> $50 \%$ de inibição), inibidores moderados (30-50\% de inibição) e inibidores fracos (<30\% de inibição).

A mais alta taxa de inibição da AChE, entre os extratos avaliados, foi obtida com o extrato aquoso de $V$. agnus-castus L. que inibiu cerca de $74 \%$ da atividade dessa enzima. Apresentaram efeito moderado na ação de inibição da Ache (30 - 50\%) o extrato etanólico de Moringa oleifera (com percentual de inibição de $47 \%$ ) e o extrato aquoso de $P$. piperoides (inibindo $40 \%$ da atividade da enzima) Os extratos aquoso e metanólico da Maytenus rigida (com percentual de inibição $4 \%$ e $7 \%$, respectivamente) e o extrato metanólico da Hyptis fruticosa (com percentual de inibição de $11 \%$ ) apresentaram fraca inibição da enzima.

Extratos cuja inibição enzimática apresente inibição maior ou igual a $50 \%$, são candidatos a fracionamentos e isolamento dos princípios ativos capazes de inibir a enzima acetilcolinesterase (Trevisan \& Macedo, 2003). O extrato metanólico das folhas da V. agnus-castus quando usados nos testes de inibição no presente estudo apresentou melhor resultado em termos de percentual de inibição. Trevisan \& Macedo (2003), em testes de inibição com extratos de plantas, obtiveram inibição de $3 \%$ com o extrato

TABELA 3. Inibição e classificação da intensidade de inibição segundo espécies e extratos utilizados.

\begin{tabular}{cccc}
\hline Nome científico & $\begin{array}{c}\text { Tipo de } \\
\text { extrato }\end{array}$ & $\begin{array}{c}\text { Percentual de } \\
\text { inibição (\%) }\end{array}$ & Intensidade da inibição \\
\hline Bauhinia cheilantha & Etanólico & 0 & - \\
Chrysobalanus icaco & Etanólico & 0 & - \\
Erythrina velutina & Aquoso & 0 & - \\
Erythrina velutina & Etanólico & 0 & - \\
Hyptis fruticosa & Etanólico & 11 & Fraca \\
Maytenus rigida & Aquoso & 4 & Fraca \\
Maytenus rigida & Etanólico & 7 & Fraca \\
Moringa oleifera & Etanólico & 47 & Moderada \\
Phoradendron piperoides & Aquoso & 40 & Moderada \\
Phoradendron piperoides & Etanólico & 0 & - \\
Sideroxylon obtusifolium & Etanólico & 0 & Potente \\
Vitex agnus-castus L. & Aquoso & 74 & - \\
Vitex agnus-castus L. & Etanólico & 0 & \\
\hline
\end{tabular}

Rev. Bras. PI. Med., Botucatu, v.14, n.4, p.624-628, 2012. 
hidroalcoólico de folhas de Bauhinia cheilantha. Já os testes com os extratos metanólico das folhas e etanólico do fruto da Vitex agnus-castus inibiram a atividade da enzima com percentuais de 12 e $18 \%$, respectivamente. Andersen et al. (2006), avaliando a atividade inibitória de AChE por 11 extratos metanólicos e aquosos de plantas medicinais da Escandinávia e de três espécies Corydalis, plantas essas utilizadas para melhorar a memória e a cognição, demonstraram significativa atividade inibitória com os extratos de Corydalis cava, Corydalis intermedia, Corydalis solida ssp. laxa and Corydalis solida ssp. Slivenensis enquanto os extratos de Ruta graveolens, Lavandula angustifolia, Rosmarinus officinalis, Petroselinum crispum and Mentha spicata exibiram baixa inibição.

Os resultados dos estudos de inibição da acetilcolinesterase permitem concluir que o extrato aquoso de $V$. agnus-castus $L$. mostrou-se o melhor quanto à inibição da $\mathrm{AChE}$. Este resultado reforça a necessidade da continuidade do estudo de forma a realizar a partição do extrato e a purificação das frações para isolar a molécula responsável pela inibição observada.

\section{AGRADECIMENTO}

Ao programa CNPq/PIBIC/UFS pela bolsa de iniciação científica dos quatro primeiros autores e à Universidade Federal de Sergipe (Edital PAIRD 2007) pela concessão de auxílios financeiros para execução deste trabalho. Ao Dr. Marcelo Ferreira Fernandes da Embrapa tabuleiros Costeiros por permitir o uso do leitor de Microplacas.

\section{REFERÊNCIA}

ADAMS, M.; GMUEDNER, F.; HAMBURGER, M. Plants traditionally used in age related brain disorders - A survey of ethnobotanical literature. Journal of Ethnopharmacology, v.113, p.363-81, 2007.

ANDSERSEN, A. et al. Screening of plants used in Danish folk medicine to treat memory dysfunction for acetylcholinesterase inhibitory activity. Journal of Ethnopharmacology, v.104, n.3, p.418-22, 2006.

LIN, H.Q. et al. Anti-acetylcholinesterase activities of traditional Chinese medicine for treating Alzheimer's disease. Chemico-Biological Interactions, v.175, p.352-4, 2008.

JUNG, M.; PARK, M. Acetylcholinesterase inhibition by flavonoids from Agrimonia pilosa. Molecules, v.12, p.21309, 2007.

MUREBWAYIREA, S. et al. Triclisia sacleuxii (Pierre) Diels (Menispermaceae), a potential source of acetylcholinesterase inhibitors. Journal of Pharmacy and Pharmacology, v.61, p.103-7, 2009.

MUKHERJEE, P.K. et al. Acetylcholinesterase inhibitors from plants. Phytomedicine, v.14, p.289-300, 2007.

NEWMAN, D.J.; CRAGG, G.M. Natural products as sources of new drugs over the last 25 years. Journal of Natural Products, v.70, p.461-77, 2007.

$\mathrm{OH}, \mathrm{M} . \mathrm{H}$. et al. Screening of Korean herbal medicines used to improve cognitive function for anti-cholinesterase activity. Phytomedicine, v.11, p.544-8, 2004.

RHEE, I.K. et al. Screening for acetylcholinesterase inhibitors from Amaryllidaceae using silica gel thin-layer chromatography in combination with bioactivity staining. Journal of Chromatography, v.915, p.217-23, 2001.

TREVISAN, M.T.S.; MACEDO, F.V.V. Seleção de plantas com atividade anticolinesterase para tratamento da doença de Alzheimer. Química Nova, v.26, n.3, p.301-4, 2003.

VINUTHA, B. et al. Screening of selected Indian medicinal plants for acetylcholinesterase inhibitory activity. Journal of Ethnopharmacology, v.109, p.359-63, 2007. 